OPEN ACCESS

Edited by:

Shoaib Usman,

Missouri University of Science and Technology, United States

Reviewed by:

Mingjun Wang

Xi'an Jiaotong University, China

Wenxi Tian,

Xi'an Jiaotong University, China

*Correspondence:

Zhang Chunyu

zhangchy5@mail.sysu.edu.cn

Specialty section:

This article was submitted to

Nuclear Energy,

a section of the journal

Frontiers in Energy Research

Received: 01 December 2020

Accepted: 23 February 2021

Published: 17 March 2021

Citation:

Zeng Z, Pan Y, Chen X, Zhang C, Yin

C, Gao S, Zhou Y, Zhang J, He X and Yuan C (2021) Three-Dimensional Modeling of Thermal-Mechanical Behavior of Accident Tolerant Fuels. Front. Energy Res. 9:636502. doi: 10.3389/fenrg.2021.636502

\section{Three-Dimensional Modeling of Thermal-Mechanical Behavior of Accident Tolerant Fuels}

\author{
Zeng Zitao ${ }^{1}$, Pan Yongyu ${ }^{1}$, Chen $X^{1}{ }^{1}$, Zhang Chunyu ${ }^{1 *}$, Yin Chunyu ${ }^{2}$, Gao Shixin ${ }^{2}$, \\ Zhou $\mathrm{Yi}^{2}$, Zhang Jie ${ }^{1}, \mathrm{He} \mathrm{Xiujie}^{1}$ and Yuan Cenxi ${ }^{1}$ \\ ${ }^{1}$ Sino-French Institute of Nuclear Engineering and Technology, Sun Yat-sen University, Zhuhai, China, ${ }^{2}$ Science and \\ Technology on Reactor System Design Technology Laboratory, Nuclear Power Institute of China, Chengdu, China
}

Considering the safety issues of the traditional $\cup_{2}$ - $\mathrm{Zr}$ fuel, a variety of accident-tolerant fuel (ATF) candidates have been proposed in recent years. Among the several ATFs, $\mathrm{U}_{3} \mathrm{Si}_{2}$, and $\mathrm{UN}$ are the two promising candidates for fuel materials owing to their high thermal conductivity and high uranium density. The FeCrAl alloy and the SiC/SiC composite material are the two promising candidates for cladding owing to their high oxidation resistance and high strength. In order to quantitatively evaluate the performance of ATFs, this study summarizes the physical models of typical ATF cladding materials (FeCrAl and $\mathrm{SiC}$ ) and pellet materials ( $\mathrm{UN}$ and $\mathrm{U}_{3} \mathrm{Si}_{2}$ ). Then a three-dimensional non-linear finite element method is applied to simulate the thermal-mechanical behavior of several typical fuel-cladding combinations, including $\cup_{2}-\mathrm{FeCrAl}, \mathrm{UN}-\mathrm{FeCrAl}, \mathrm{U}_{3} \mathrm{Si}_{2}$-FeCrAl, $\mathrm{U}_{3} \mathrm{Si}_{2}-\mathrm{Zr}$, and $\mathrm{U}_{3} \mathrm{Si}_{2}-\mathrm{SiC}$. The important physical quantities, such as the fuel centerline temperature, the deformation of the pellet and the cladding as well as the pellet-cladding mechanical interaction (PCMI) were studied. The fission gas release model was also verified and improved.

Keywords: accident-tolerant fuel, multiphysics coupling, finite element method, fisson gas release, creep, swelling

\section{INTRODUCTION}

The performance of fuel elements is a key factor ensuring the safety and economy of nuclear reactors. After the Fukushima accident in 2011, great efforts have been put on investigating various accident tolerant fuels (ATFs) to improve the safety of fuels. In order to fully or partially replace the traditional $\mathrm{UO}_{2}$-Zircaloy fuels, ATF not only needs to provide higher safety and reliability but also is expected to have a competitive economic benefit (such as higher burnup, longer lifetime, etc.). Among the several ATF materials, $\mathrm{U}_{3} \mathrm{Si}_{2}$ and $\mathrm{UN}$ are the two promising candidates for fuel owing to their higher thermal conductivity and higher uranium density (Metzger, 2016), the FeCrAl alloy and the $\mathrm{SiC} / \mathrm{SiC}$ composite material are the two promising candidates for cladding owing to their high oxidation resistance and high strength (Sweet, 2018; Qiu et al., 2020).

Since the in-pile test is an extremely expensive and long-term process, high-fidelity multiphysics modeling has become an indispensable tool for evaluating the performance of nuclear fuels. With the support of the Consortium for Advanced Simulation of Light Water Reactors (CASL) project, the Idaho National Laboratory has begun to develop a new generation of multiscale and multiphysics simulation program for fuel performance evaluation, i.e., BISON, since 2010. The French Atomic Energy Commission (CEA) and Electricite De France (EDF) have also jointly developed a multiscale and multiphysics fuel performance analysis program, i.e., ALCYONE, for 
pressurized water reactor (PWR). In recent years, several studies have been conducted for modeling the performances of ATFs. Liu et al. (2018) studied the performance of $\mathrm{U}_{3} \mathrm{Si}_{2}-\mathrm{FeCrAl}$ fuel in LWR using the CAMPUS code based on the COMSOL framework. He et al. (2018) also did a preliminary evaluation of the performance of $\mathrm{U}_{3} \mathrm{Si}_{2}-\mathrm{FeCrAl}$ using the BEEs code based on MOOSE framework. $\mathrm{U}_{3} \mathrm{Si}_{2}-\mathrm{SiC}$ fuel performance analysis was also done by Li and Shirvan (2019) using BISON.

However, a comprehensive study is still absent for the thermal-mechanical performance and fission gas release behavior of ATF materials under LWR conditions. In order to quantitatively evaluate the thermo-mechanical behavior of typical ATFs, this study evaluated the typical fuel-cladding combinations such as UN-FeCrAl, $\mathrm{U}_{3} \mathrm{Si}_{2}-\mathrm{FeCrAl}, \mathrm{UO}_{2}$ $\mathrm{FeCrAl}, \mathrm{U}_{3} \mathrm{Si}_{2}-\mathrm{Zr}$, and $\mathrm{U}_{3} \mathrm{Si}_{2}-\mathrm{SiC}$ by using the non-linear three-dimensional finite element method. The fuel centerline temperature, the deformation of the pellet and the cladding, as well as the pellet-cladding mechanical interaction (PCMI) of different fuel-cladding combinations are analyzed and compared. In addition, this study verified and improved the fission gas release (FGR) model, and investigated the fission gas release behavior of ATF pellets during normal operations of PWR.

\section{THEORY AND MODELS}

\section{Thermo-Mechanical Modeling by Finite Element Method}

The thermal-mechanical behaviors of the fuel elements are described by the equations of energy conservation and momentum conservation. The equation of energy conservation is given as:

$$
\rho c \partial T(x, t) / \partial t-k \Delta T(x, t)=g, x \in \Omega, t \in I
$$

where $\rho$ is the mass density, $c$ is specific heat, $T$ is the temperature, $k$ is the thermal conductivity, $g$ is the rate of heat generated per unit volume, $\Omega$ is the spatial domain, and $I$ is the temporal range.

And the equation of momentum conservation is given as:

$$
\sigma_{i j, j}+f_{i}=0, i, j=1,2,3, x \in \Omega, t \in I
$$

where $\sigma_{i j}$ is the stress, $f_{i}$ is the body force.

The stress is given as:

$$
\sigma=\mathbf{C}:\left(\varepsilon-\varepsilon^{i n}-\alpha \Delta T\right)
$$

where $\sigma$ is the stress tensor, $\mathbf{C}$ is the stiffness matrix, $\varepsilon$ is the strain tensor, $\varepsilon^{i n}$ is the component of the inelastic strain tensor, $\alpha$ is the coefficient of linear expansion, and “:” denotes the contraction operation.

Under the conditions of irradiation and high temperature, the density, the specific heat and the thermal conductivity of fuel materials are dependent on temperature and burnup. Thus, the above-mentioned equation of energy conservation is non-linear. At the same time, the fuel and the cladding materials undergo complex non-linear deformations such as creep and swelling.
Therefore, the above equation of momentum conservation is also non-linear. In this study, the general-purpose non-linear finite element software, i.e., ABAQUS, is used to solve the above conservation equations. The thermal and the mechanical constitutive behaviors of the material are defined by user-defined subroutines in ABAQUS (Figure 1). The heat conduction of the pellet-cladding gap and the pressure of the gas filling the gap are related to the released fission gas. The gas release behavior is also defined by subroutines. The local power distribution and the local burnup distribution of the fuel are obtained by Monte Carlo simulation and embedded in the subroutines in the form of fitted polynomials.

In this study, the sequential coupling technique is adopted to solve the coupled thermo-mechanical problem. The calculation results show that the efficiency and numerical stability of the sequential coupling algorithm are better than the fully coupled algorithm. The Newton algorithm is used for non-linear iteration, and the subroutines are called at each integration point in each iteration to obtain the physical parameters required to compute the elemental mass matrix, the stiffness matrix and the load vector. The flowchart of solving the above-mentioned equations by the non-linear finite element method is shown in Figure 1. It should be noticed that this paper uses an explicit method to calculate and update the fission gas release.

\section{Thermo-Mechanical Model of ATF Materials \\ Thermal Models \\ Thermal Conductivity}

Thermal conductivity is a determinant parameter of the thermomechanical properties of fuel materials. It affects both the thermal behavior and the mechanical behavior (such as thermal creep) of the fuel. High thermal conductivity can effectively reduce the temperature and its gradient of the fuel, which is generally beneficial to improve the performance of fuels.

In this study, the model of the thermal conductivity of $\mathrm{U}_{3} \mathrm{Si}_{2}$ from the Handbook (White, 2018) is adopted. The Hayes Model (Hayes et al., 1990a) is adopted for the model of thermal conductivity of UN. The thermal conductivity of FeCrAl is described in the report of Yamamoto et al. (2017). The thermal conductivity of $\mathrm{SiC} / \mathrm{SiC}$ composite is described in the report of Koyanagi and Katoh (2018). Figure 2 shows that the thermal conductivity of fresh $\mathrm{UN}$ and $\mathrm{U}_{3} \mathrm{Si}_{2}$, which is remarkly higher than that of $\mathrm{UO}_{2}$. The high thermal conductivity is one of the most prominent features of ATFs.

\section{Specific Heat}

In this work, the specific heat model of $\mathrm{U}_{3} \mathrm{Si}_{2}$ is also adopted from the Handbook (White, 2018) for consistency with the thermal conductivity model. For UN, the Hayes Model (Hayes et al., 1990b) is adopted. The fitting formula of the specific heat of FeCrAl consists of two segments. The first segment is applicable to the temperature above the Curie temperature but below the melting point, while the second segment is a third-order polynomial applicable to the temperature below the Curie temperature (Raju et al., 2009). With the temperature range from 200 to $2,400 \mathrm{~K}$, the specific heat of $\mathrm{SiC}$ can be 


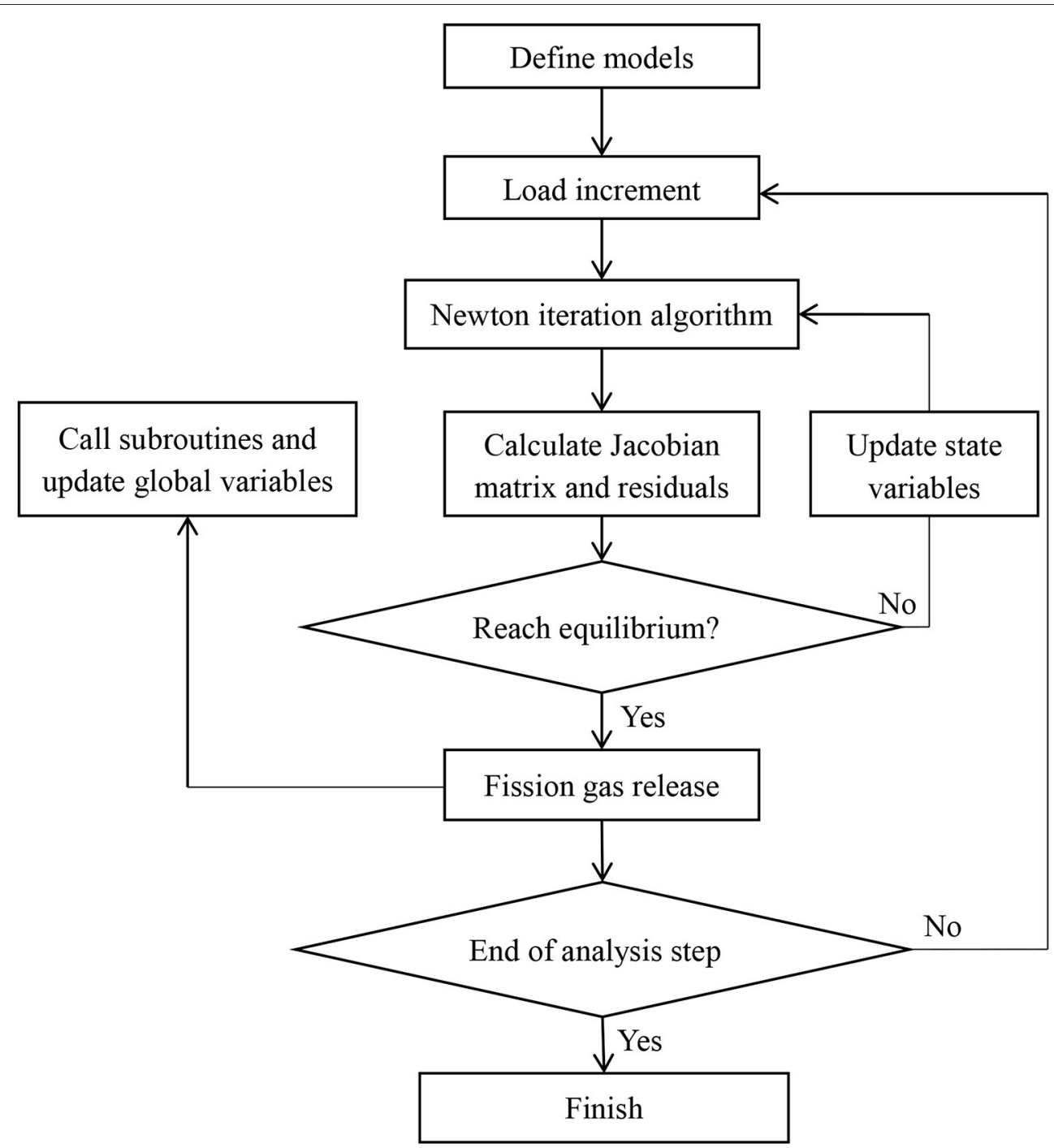

FIGURE 1 | Flowchart of computation.

approximately expressed by a temperature-dependent function (Snead et al., 2007).

\section{Mechanical Models \\ Creep Model}

As fuel rods are exposed in an environment with high temperature, high pressure and high irradiation, the creep effect has a significant influence on the deformation of fuels. For $\mathrm{U}_{3} \mathrm{Si}_{2}$, Metzger (2016) proposes a creep model which accounts for athermal and thermal creep, i.e., when the temperature is below $0.45 T_{\text {melt }}\left(=872.0 \mathrm{~K}\right.$, where $T_{\text {melt }}$ is the melting point), athermal creep is activated. Above $872.0 \mathrm{~K}$, creep is thermally activated. Thermal creep is driven by two different mechanisms that under low stress, i.e., $\sigma / G \leq 10^{-4}$, where $\sigma$ is the stress and $G$ is the shear modulus, the creep is governed by grain boundary diffusion (Coble creep). And under high stress, i.e., $\sigma / G>10^{-4}$, the creep is driven by dislocation slip and climb (dislocation creep).
For UN, the irradiation creep is dominant under PWR conditions. Therefore, it is acceptable to neglect thermal creep in the present study. The irradiation creep rate in $s^{-1}$ for $\mathrm{UN}$ is given as (Feng et al., 2011):

$$
\dot{\varepsilon_{I}}=1.81 \times 10^{-26}\left(1+1250 p^{2}\right) \sigma . f
$$

where $\sigma$ is the stress in $\mathrm{MPa}, p$ is the porosity, $f$ is the fission density in fissions $/ \mathrm{cm}^{3}$ s.

Yamamoto et al. (2017) proposes a generalized thermal creep equation for all types of FeCrAl alloys:

$$
\dot{\varepsilon}_{c, t h}=0.83 \cdot \sigma^{7.1} \cdot \exp \left(-\frac{39211}{T}\right)
$$

where $\dot{\varepsilon}_{c, t h}$ is the strain rate in $s^{-1}, \sigma$ is the stress in MPa and $T$ is the temperature in $\mathrm{K}$ with $623 \mathrm{~K} \leq \mathrm{T} \leq 1473 \mathrm{~K}, 1 \mathrm{MPa} \leq \sigma \leq$ $150 \mathrm{MPa}$. 


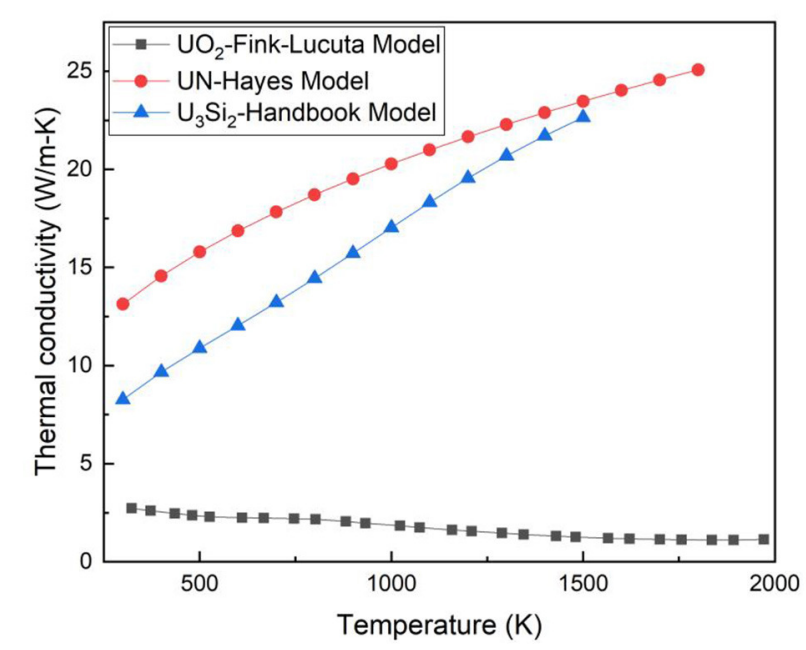

FIGURE 2 | Thermal conductivities of fresh $\bigcup_{3} \mathrm{Si}_{2}$ (White, 2018), UN (Hayes et al., 1990a), and $\cup_{2}$ (Williamson, 2011).

The irradiation creep of $\mathrm{FeCrAl}$ is the same as that adopted by BISON (Hales et al., 2015),

$$
\dot{\varepsilon}_{c, i r r}=4.5 \times 10^{-32} \sigma \Phi
$$

where $\dot{\varepsilon}_{c, \text { irr }}$ is the strain rate in $s^{-1}, \sigma$ is the effective stress in $\mathrm{MPa}$ and $\Phi$ is the neutron flux in $n / m^{2} s$.

It is proposed by Koyanagi et al. (2017) that the thermal creep rates of SiC-based materials are very low at the temperature below $\sim 1,000^{\circ} \mathrm{C}$. Therefore, for normal operation temperatures, the thermal creep can be neglected for thermo-mechanical modeling of $\mathrm{SiC}$ cladding. Moreover, the irradiation creep of $\mathrm{SiC}$ can be neglected for modeling purpose as well (Koyanagi et al., 2016).

\section{Swelling}

Swelling is an important form of deformation of fuel materials. The swelling of pellets directly affects the gap width, thereby affecting the gap heat conduction and the PCMI.

An empirical burnup-dependent expression for the swelling of $\mathrm{U}_{3} \mathrm{Si}_{2}$ has been proposed by Metzger et al. (2014) by using the experimental data from Finlay et al. (2004). The total volumetric fuel swelling consists of the normal swelling part and the densification part. It is assumed that the densification behavior of $\mathrm{U}_{3} \mathrm{Si}_{2}$ is the same as that of $\mathrm{UO}_{2}$ which is modeled by the ESCORE empirical model (Gamble et al., 2019).

It is recommended by Feng et al. (2011) that the total swelling rate of $\mathrm{UN}$ is,

$$
\Delta V / V[\%]=0.9 \times B u
$$

where $B u$ is burnup in FIMA. Irradiation-induced densification is neglected for UN fuel (Feng et al., 2011).

For cladding, the main contribution of the swelling is the irradiation-induced swelling. A simple linear model scaling with neutron flux is used to describe the $\mathrm{FeCrAl}$ swelling behavior according to the report by Sweet et al. (2018) and BISON's manual (Hales et al., 2015):

$$
\dot{\varepsilon}_{\mathrm{sw}, i r r}=4.5 \times 10^{-29} \Phi
$$

where $\dot{\varepsilon}_{s w \text {,irr }}$ is the strain rate in $s^{-1}$ and $\Phi$ is the neutron flux in $n / m^{2} s$.

The irradiation swelling of $\mathrm{SiC}$ is expressed by the model of Katoh et al. (2018):

$$
S=S_{S}\left[1-\exp \left(-\frac{\gamma}{\gamma_{c}}\right)\right]^{\frac{2}{3}}
$$

where $S$ is swelling strain, $\gamma$ is displacement damage in dpa, $\gamma_{C}$ and $S_{S}$ are functions of temperature:

$$
\begin{aligned}
\gamma_{C}= & -0.57533+3.3342 \times 10^{-3} T-5.3970 \times 10^{-6} T^{2} \\
& +2.9754 \times 10^{-9} T^{3} \\
S_{S}= & 5.8366 \times 10^{-2}-1.0089 \times 10^{-4} T+6.9368 \times 10^{-8} T^{2} \\
& -1.8152 \times 10^{-11} T^{3}
\end{aligned}
$$

where $T$ is the temperature in $\mathrm{K}$ with a valid range from 473 to $1,073 \mathrm{~K}$.

\section{Fission Gas Release}

The release of fission gas mainly includes two parts, i.e., the thermal release and the athermal release (Olander, 1976). Both the two release mechanisms are considered by adding the individual release fraction.

Forsberg-Massih model proposed by Forsberg and Massih (1985) is chosen as the thermal release model in this paper. Considering the predicted release ratio by the Forsberg-Massih model is conservative, this paper calibrates the dominant parameters according to the experimental measurement of $\mathrm{UO}_{2}$ fuel. For different fuel materials, the gas atomic diffusion coefficient within the grain may vary.

The diffusion coefficient of fission gas within $\mathrm{U}_{3} \mathrm{Si}_{2}$ grains was proposed by Barani et al. (2019)):

$$
D=5.91 \times 10^{-6} \cdot \exp \left(-4.41 \times 10^{-19} / k T\right)
$$

where $k=1.380649 \times 10^{-23} \mathrm{~J} / \mathrm{K}$ is the Boltzmann constant, $T(K)$ is the temperature.

The diffusion coefficient of fission gas within UN grain was proposed by Feng et al. (2011):

$$
\begin{aligned}
D= & F_{p}\left(8.22 \times 10^{-31} \cdot F_{B} \cdot f+2.37 \times 10^{-10} \cdot e^{\frac{-18800}{T}}\right. \\
& \left.+10^{-18} \cdot \frac{f}{K^{2} T^{2}} \cdot e^{\frac{-18400}{T}}\right)
\end{aligned}
$$

where $D\left(\mathrm{~cm}^{2} / \mathrm{s}\right)$ is the diffusion coefficient of $\mathrm{UN}, F_{p}=$ $e^{-(\rho-80) / 3.4}$ is a factor related to the relative density $\rho(\% T D)$, $F_{B}=30+B u$ with $B u$ the burnup in $M W d / k g U, f$ (fissons $/ \mathrm{cm}^{3} \mathrm{~s}$ ) is the fission rate density, $K(W / m K)$ is the thermal conductivity, $T(K)$ is the temperature. 


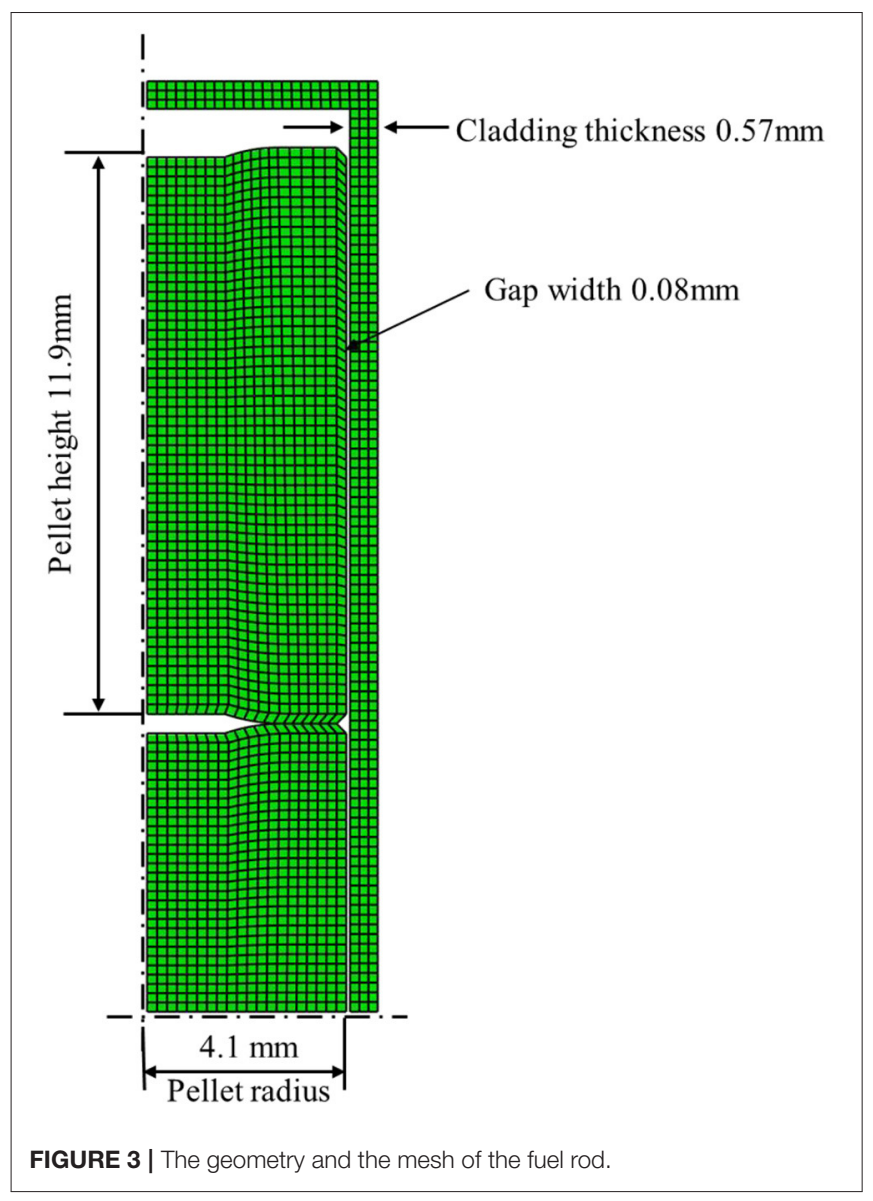

The athermal release of fission gas can be described by the COPERNIC FGR model (Bernard et al., 2002). Neglecting the recoil contribution, the athermal FGR fraction is of the form,

$$
F=C_{1}\left(\frac{S}{V}\right) B
$$

where $F$ is the athermal FGR fraction, $C_{1}=1.3 \times$ $10^{-7} \mathrm{~cm} /(\mathrm{MWd} / \mathrm{kgU})$ is a model parameter, $S / V$ is the specific surface of the fuel grain $\left(\mathrm{cm}^{-1}\right)$ and $B$ is burnup $(M W d / \mathrm{kgU})$.

\section{Fuel Rod Model}

The simplified fuel rod with three pellets is considered in the simulation. The axisymmetric geometric configuration is illustrated in Figure 3. The major operation parameters are listed in Table 1.

The axisymmetric thermal-mechanical coupling element, i.e., CAX4T, is adopted. An element size of around $0.2 \mathrm{~mm}$ has been assigned for both the pellet and the cladding. Meshinsensitivity has been ensured. The coupled temperaturedisplacement procedure is chosen to perform the analysis.

\section{RESULTS AND DISCUSSION}

\section{Model Validation}

Considering experimental data of ATFs is rather limited, comparison with other literature work can provide a reference for
TABLE 1 | Operation parameters.

\begin{tabular}{lc}
\hline Parameter & Value \\
\hline Initial pressure of filled gas & $2 \mathrm{MPa}$ \\
Filled gas & $\mathrm{He}$ \\
Linear power & $20 \mathrm{~kW} / \mathrm{m}$ \\
Convection coefficient of cladding & $7,500 \mathrm{~W} / \mathrm{m}^{2} \mathrm{~K}$ \\
Coolant temperature & $530 \mathrm{~K}$ \\
Coolant pressure & $15.5 \mathrm{MPa}$ \\
Fuel enrichment & $5 \%$ \\
Fast neutron flux & ${ }^{*} \dot{\Phi}=\mathrm{CP}$ \\
Fuel emissivity & 0.8 \\
Cladding emissivity & 0.8
\end{tabular}

* $\dot{\Phi}$ represents the neutron flux, $c$ is a constant with value of $3 \times 10^{13} \mathrm{n} /\left(\mathrm{m}^{2} \mathrm{~s}\right) /(\mathrm{W} / \mathrm{m}), P$ is the linear heat generation rate $(W / m)$.

the reliability of the present results. The predicted behavior of the $\mathrm{U}_{3} \mathrm{Si}_{2}-\mathrm{FeCrAl}$ combination is compared with that reported in $\mathrm{He}$ et al.'s work (2018). The geometry of the fuel and the boundary conditions (LHGR, coolant pressure, coolant temperature, etc.) are set the same as those in He's work, i.e., the pellet radius, the cladding thickness and the initial gap width are set as $4.3,0.37$, and $0.08 \mathrm{~mm}$, respectively. The fuel centerline temperature, the evolution of the gap width, the gap heat transfer coefficient and the plenum pressure are compared in Figure 4. The maximum average burnup in He's work is around $40 \mathrm{MWd} / \mathrm{kgU}$ while it reaches $60 \mathrm{MWd} / \mathrm{kgU}$ in the present study.

As shown in Figure 4, fairly good agreement is obtained for fuel centerline temperature because similar thermal conductivity models of fuel and cladding are adopted by both work. The tendency of the evolution of gap width is similar because the same fuel densification model and fuel swelling model are adopted. The deviation of the gap width is mainly due to the different mechanical models of the cladding. In He's work, the thermal expansion of cladding adopts Shimizu's model (1965). While in our work, the thermal expansion of cladding is taken from Yamamoto's work (2017) and the value is much higher than that of Shimizu's model. The gap heat transfer coefficient is similar at the beginning due to the same gap heat transfer model are adopted. However, it is influenced by the gap width after $20 \mathrm{MWd} / \mathrm{kgU}$ burnup. As for plenum pressure, the growth of plenum pressure of the present work is more rapid than that in He's work due to an earlier gap closure and the fission gas release.

\section{Influence of Pellet Materials}

In order to compare the performance of the advanced fuels, the cladding material is fixed as $\mathrm{FeCrAl}$ and the behaviors of $\mathrm{UO}_{2}, \mathrm{U}_{3} \mathrm{Si}_{2}$, and $\mathrm{UN}$ are, respectively studied. The fuel centerline temperature, the gap width, the stress distribution as well as the pellet-cladding mechanical interaction (PCMI) are studied.

Figure 5 shows the evolution of the fuel centerline temperature of the three combinations. It is obvious that the centerline temperatures of the two ATFs is $400 \sim 600 \mathrm{~K}$ lower than that of $\mathrm{UO}_{2}$, due to their relatively high thermal conductivity. It is also noticed that for the $\mathrm{U}_{3} \mathrm{Si}_{2}-\mathrm{FeCrAl}$ combination, the temperature remains nearly constant after 55 

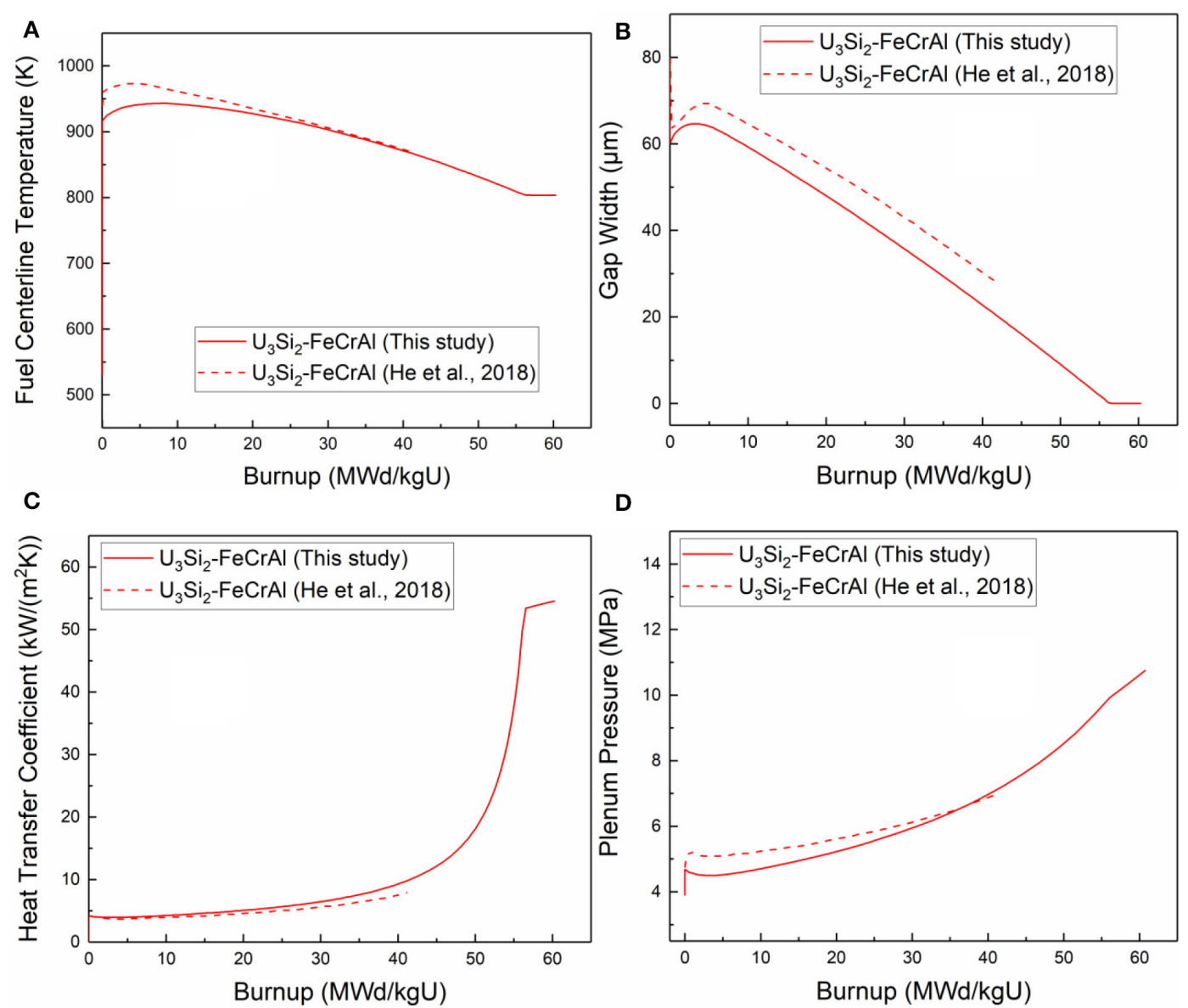

FIGURE 4 | Comparison of (A) Fuel centerline temperature, (B) Gap width, (C) Gap heat transfer coefficient, (D) Plenum pressure.

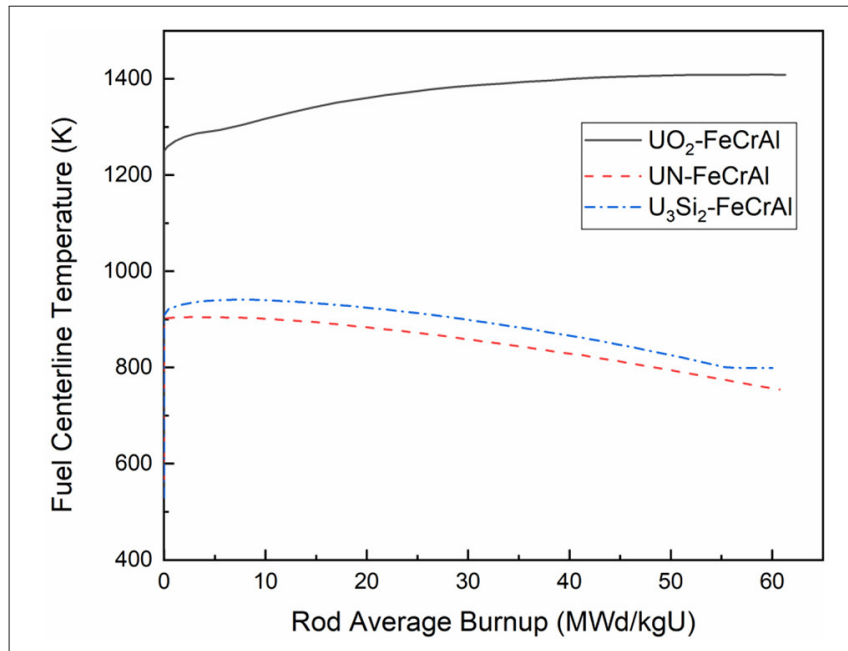

FIGURE 5 | Comparison of fuel centerline temperature of $\mathrm{UO}_{2}, \mathrm{UN}$, and $\mathrm{U}_{3} \mathrm{Si}_{2}$ with the FeCrAl cladding.
$M W d / k g U$ when the PCMI occurs. Owing to a much smaller gap size of $\mathrm{U}_{3} \mathrm{Si}_{2}-\mathrm{FeCrAl}$ shown in Figure 6, the heat conduction of the gap is significantly higher than that of $\mathrm{UO}_{2}-\mathrm{FeCrAl}$. It can reduce the thermal resistance of the fuel rod thus resulting in a decrease of the fuel centerline temperature.

Figure 6 illustrates the variation of gap width with the average burnup. In the beginning, thermal expansion is dominant and as a consequence, $\mathrm{U}_{3} \mathrm{Si}_{2}-\mathrm{FeCrAl}$ has the smallest initial gap width which can be attributed to the highest thermal expansion coefficient of $\mathrm{U}_{3} \mathrm{Si}_{2}$. As the densification of $\mathrm{UN}$ is not considered, an increase of the gap width does not appear. It was also found that the gap becomes small gradually with burnup due to the fuel swelling. $\mathrm{U}_{3} \mathrm{Si}_{2}$ has the highest swelling rate, which results in the earliest gap closure.

The distribution of the temperature and the maximum principal stress at the initial burnup is shown in Figures 7, 8 respectively. It is noticed that the maximum principal stress of $\mathrm{UO}_{2}$ is nearly $650 \mathrm{MPa}$ due to its higher temperature gradient. It will cause the fuel cracking in the radial direction considering the tensile strength of $\mathrm{UO}_{2}$ is only $110 \mathrm{MPa}$. It can be seen that 


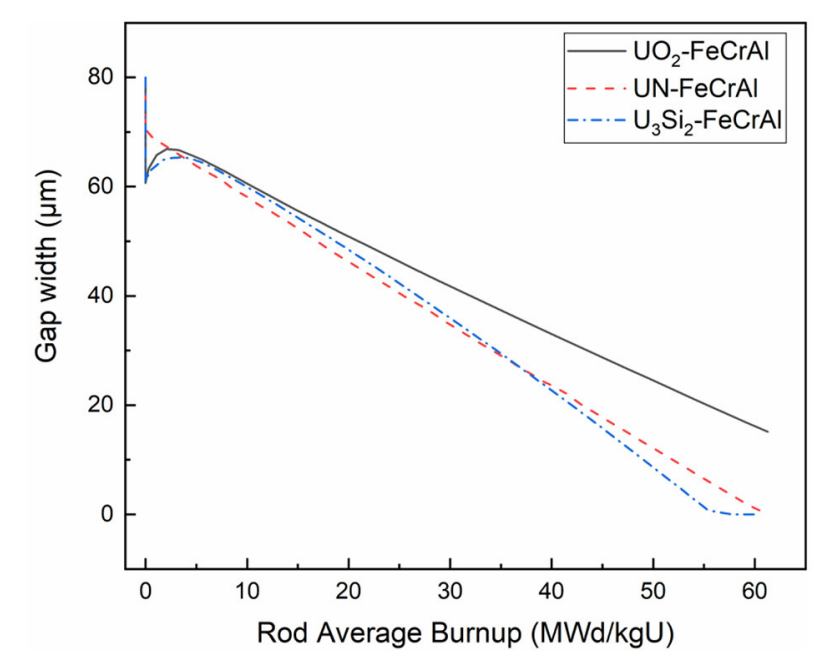

FIGURE 6 | Evolution of gap width of UO2-FeCrAl, UN-FeCrAl, and U3Si2-FeCrAl with burnups.

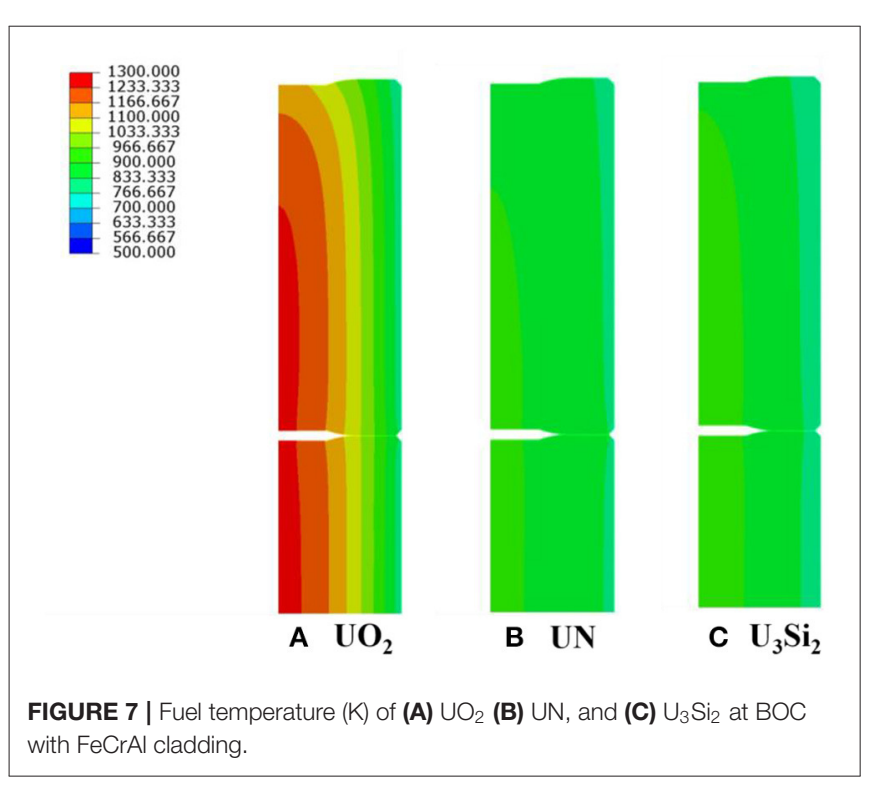

$\mathrm{U}_{3} \mathrm{Si}_{2}$ and $\mathrm{UN}$ have a much flatter distribution of temperature, which results in a much lower temperature gradient. Thus, the maximum principal stress for both $\mathrm{U}_{3} \mathrm{Si}_{2}$ and $\mathrm{UN}$ is $<200 \mathrm{MPa}$ which greatly reduces the fuel fragmentation and relocation.

\section{Influence of Cladding Materials}

In order to compare the effects of cladding materials, the fuel material is fixed as $\mathrm{U}_{3} \mathrm{Si}_{2}$ and three types of cladding materials, i.e., $\mathrm{FeCrAl}, \mathrm{SiC}$, and $\mathrm{Zr}$, are respectively investigated. The evolution of the fuel centerline temperature of the fuels with different claddings is shown in Figure 9. For all the claddings, there is a continuous temperature decrease until the closure of the pellet-cladding gap. During the whole evolution, the fuel centerline temperature of $\mathrm{U}_{3} \mathrm{Si}_{2}-\mathrm{SiC}$ is evidently higher than that of $\mathrm{U}_{3} \mathrm{Si}_{2}-\mathrm{FeCrAl}$ and $\mathrm{U}_{3} \mathrm{Si}_{2}-\mathrm{Zr}$. This is because the thermal conductivity of the irradiated $\mathrm{SiC}$ (about 3.6 W/m.K) (Koyanagi
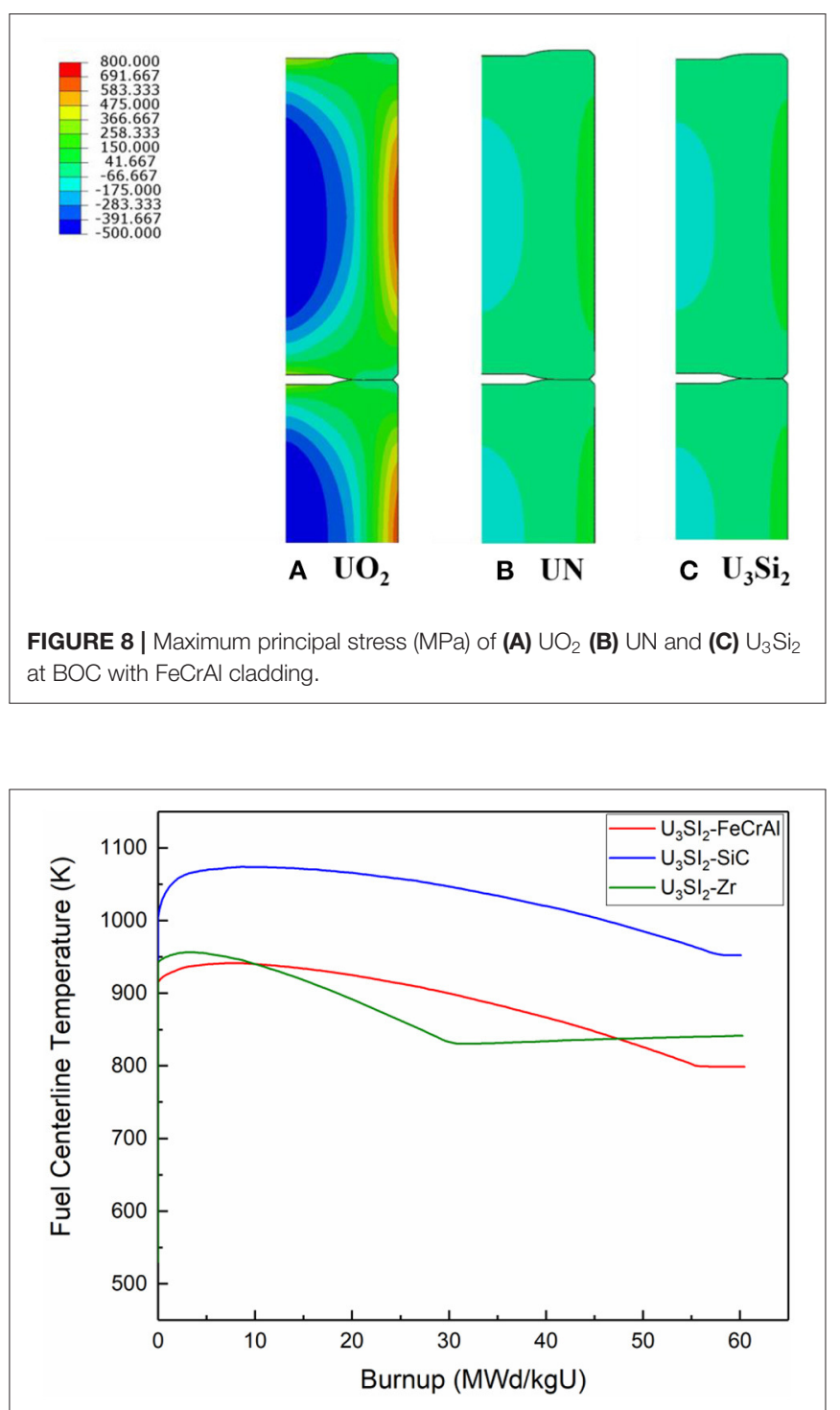

FIGURE 9 | Fuel centerline temperature of three types of cladding with $\mathrm{U}_{3} \mathrm{Si}_{2}$.

and Katoh, 2018) is notably lower than that of FeCrAl and $\mathrm{Zr}$ (both range from around $12-22 \mathrm{~W} / \mathrm{m} \cdot \mathrm{K}$ when temperature varies from $400-1,000 \mathrm{~K}$ ) (Yamamoto et al., 2017).

It is also noticed that there is no apparent difference between the maximum fuel centerline temperatures of $\mathrm{U}_{3} \mathrm{Si}_{2}-\mathrm{FeCrAl}$ and $\mathrm{U}_{3} \mathrm{Si}_{2}-\mathrm{Zr}$ due to the similar thermal conductivity of $\mathrm{FeCrAl}$ and $\mathrm{Zr}$. The fuel centerline temperature of $\mathrm{U}_{3} \mathrm{Si}_{2}-\mathrm{Zr}$ decreases more rapidly than that of $\mathrm{U}_{3} \mathrm{Si}_{2}-\mathrm{FeCrAl}$ due to the higher pelletcladding gap heat transfer which is mainly caused by their different gap widths. Moreover, due to a later gap closure of $\mathrm{U}_{3} \mathrm{Si}_{2}-\mathrm{FeCrAl}$, the fuel centerline temperature of $\mathrm{U}_{3} \mathrm{Si}_{2}-\mathrm{FeCrAl}$ finally reaches a lower level.

The evolution of the pellet-cladding gap width is shown in Figure 10. The $\mathrm{U}_{3} \mathrm{Si}_{2}-\mathrm{Zr}$ combination is found to have the earliest gap closure, indicating an earliest pellet-cladding mechanical interaction. This also signifies that the adoption of ATF claddings can effectively delay the gap closure as well as the PCMI. 


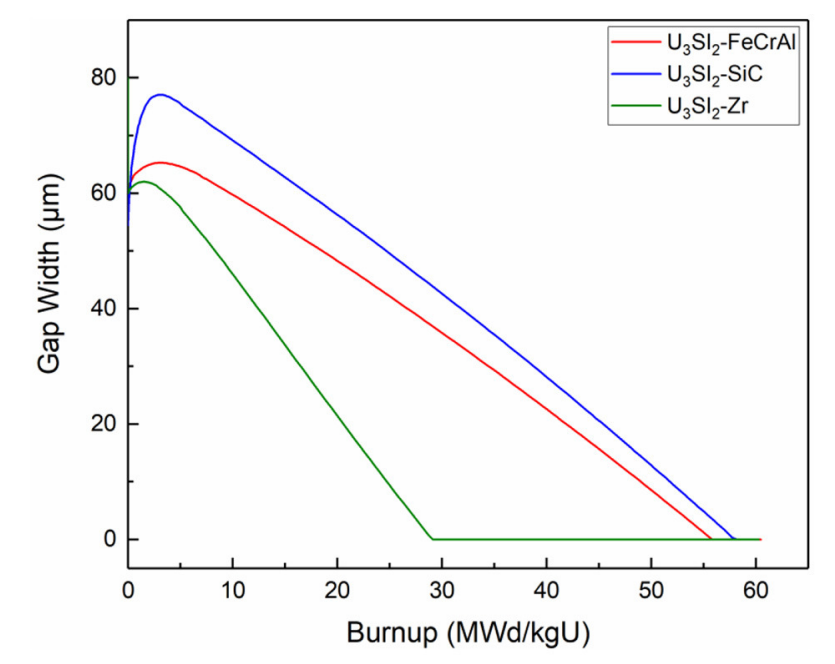

FIGURE 10 | Influence of cladding material on evolution of gap width (fuel: $\left.\mathrm{U}_{3} \mathrm{Si}_{2}\right)$.

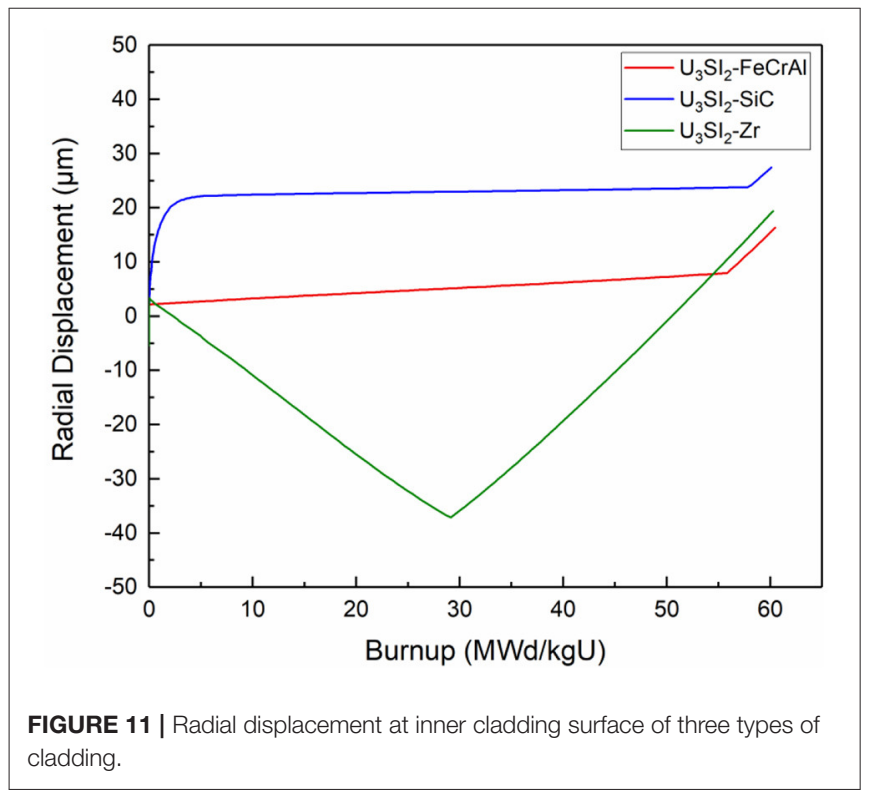

In order to find out the influences of different claddings on the gap width, the radial displacement at the inner surface of cladding is presented in Figure 11. Under the pressure of coolant, the Zircaloy cladding has a displacement toward pellets due to the creep effect. After the PCMI occurs, its displacement has an outward increase driven by the fuel deformation. For FeCrAl and $\mathrm{SiC}$ claddings, the pressure of coolant has a negligent effect on the radial displacement due to the lower creep rate. For the radial displacement of $\mathrm{SiC}$ cladding, there is an apparent increase at first due to its much higher irradiation swelling until the swelling is saturated.

Figure 12 presents the evolutions of hoop stress of ATF claddings compared with that of Zircaloy cladding. The stresses are extracted from the outer radius of cladding at the mid-plane of the fuel rod. The hoop stress is negative (compressive) due to the pressure of coolant before the gap closure, and shows a sudden increase when the fuel and the cladding contacts. It is evident that the stress in both $\mathrm{FeCrAl}$ and $\mathrm{SiC}$ cladding is higher than that in Zircaloy cladding after the contact. This is expected because of the higher stiffness as well as the lower creep of both FeCrAl and SiC.

\section{Gas Release Behavior Model Validation}

In this paper, the fission gas release of different ATF fuels is simulated by choosing appropriate fission gas atomic diffusion coefficient. Considering the insufficient experimental data, this paper only compares the results by other software for the UN-SiC fuel combination. For convenience of comparison, the parameters used in the study are consistent with those in the literature (Rice, 2015).

In this paper, the simulation results of UN-SiC fission gas release behavior and the comparison with the simulation results of other programs are shown in Figure 13. It can be found that the results of this paper are similar to the results of BISON program and FRAPCON program. The simulated thermal release in this program starts at the burnup of $32 \mathrm{MWd} / \mathrm{KgU}$ and reaches a total release ratio of about $3.3 \%$ at $60 \mathrm{MWd} / \mathrm{KgU}$.

\section{Comparison of Fission Gas Release Behavior of Different Fuels}

In order to study the fission gas release behavior of different fuels, $\mathrm{FeCrAl}$ is chosen as the cladding material. The predicted fission gas release of $\mathrm{U}_{3} \mathrm{Si}_{2}, \mathrm{UN}$, and $\mathrm{UO}_{2}$ are shown in Figure 14 .

In this case, $\mathrm{UO}_{2}$ begins the thermal release at about $20 \mathrm{MWd} / \mathrm{KgU}$, much earlier than the $60 \mathrm{MWd} / \mathrm{KgU}$ of UN. The fission gas release of $\mathrm{U}_{3} \mathrm{Si}_{2}$ is dominated by athermal release at burnup to $66 \mathrm{MWd} / \mathrm{KgU}$. The final fission gas release ratio of $\mathrm{UO}_{2}$ reaches about $8 \%$, which is much higher than that of $\mathrm{UN}$ and $\mathrm{U}_{3} \mathrm{Si}_{2}$. As can be seen from Figure 5, the temperature of $\mathrm{UO}_{2}$ fuel is about $500 \mathrm{~K}$ higher than that of the other two fuels. This is the main reason that leads to the difference of fission gas thermal release and finally causes the great difference in total release ratio.

\section{SUMMARY}

The thermal-mechanical models of typical ATFs, including $\mathrm{U}_{3} \mathrm{Si}_{2}$, UN for fuel materials, $\mathrm{FeCrAl}$ and $\mathrm{SiC}$ for cladding materials are summarized. Furthermore, the fission gas release models have been investigated and analyzed. Using non-linear finite element simulation, the thermal-mechanical behaviors of $\mathrm{UO}_{2}-\mathrm{FeCrAl}, \mathrm{UN}-\mathrm{FeCrAl}, \mathrm{U}_{3} \mathrm{Si}_{2}-\mathrm{FeCrAl}, \mathrm{U}_{3} \mathrm{Si}_{2}-\mathrm{Zr}$, and $\mathrm{U}_{3} \mathrm{Si}_{2}-$ $\mathrm{SiC}$ combinations have been studied.

The conclusions are summarized as follows,

1. Compared with $\mathrm{UO}_{2}$, the ATFs have a lower fuel centerline temperature and flatter radial temperature profile owing to the higher thermal conductivities of ATFs. A lower temperature gradient contributes to a flatter stress distribution and thus reducing the severity of fuel fragmentation. Even though the high swelling rate of $\mathrm{U}_{3} \mathrm{Si}_{2}$ and $\mathrm{UN}$ causes an earlier PCMI, the gap closure can further reduce the fuel centerline temperature.

2. Compared with the Zircaloy cladding, the SiC cladding causes higher fuel centerline temperature due to the degradation 
A

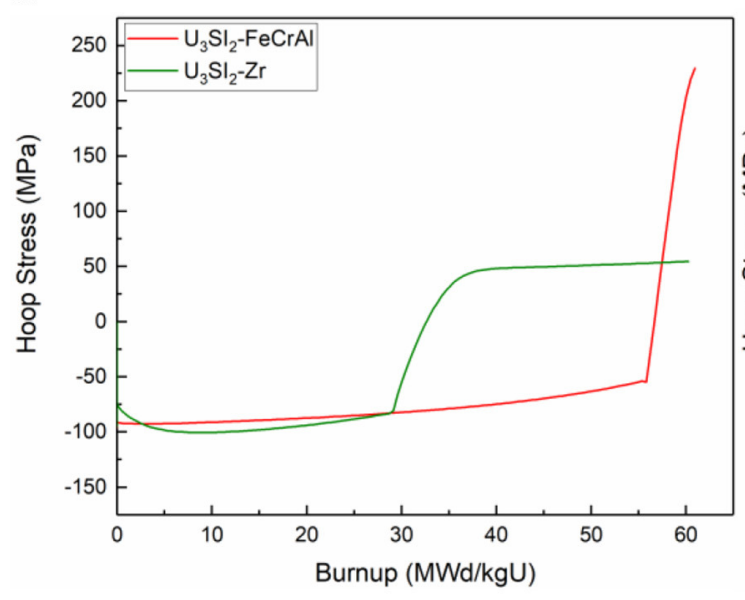

B

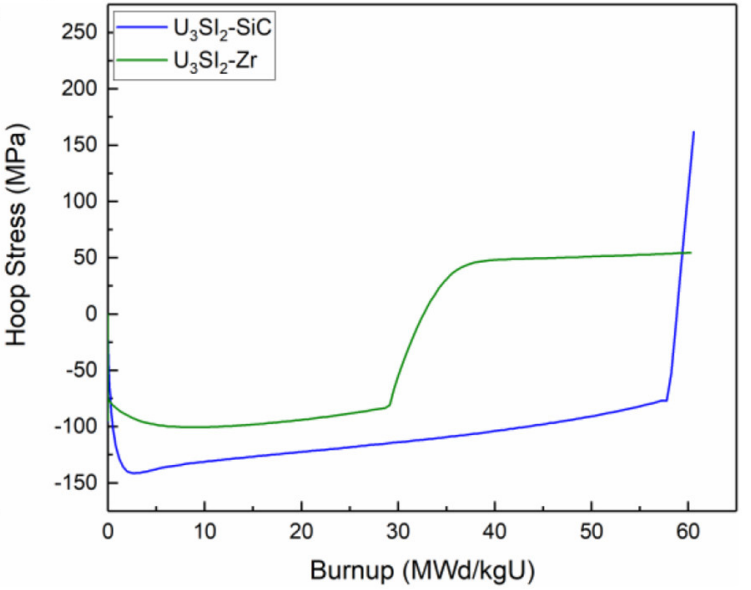

FIGURE 12 | Comparison of cladding hoop stress evolution of $U_{3} \mathrm{Si}_{2}-\mathrm{FeCrAl}$ and $U_{3} \mathrm{Si}_{2}-\mathrm{Zr}(\mathbf{A})$ and of $U_{3} \mathrm{Si}_{2}-\mathrm{SiC}_{\text {and }} U_{3} \mathrm{Si}_{2}-\mathrm{Zr}$ (B).

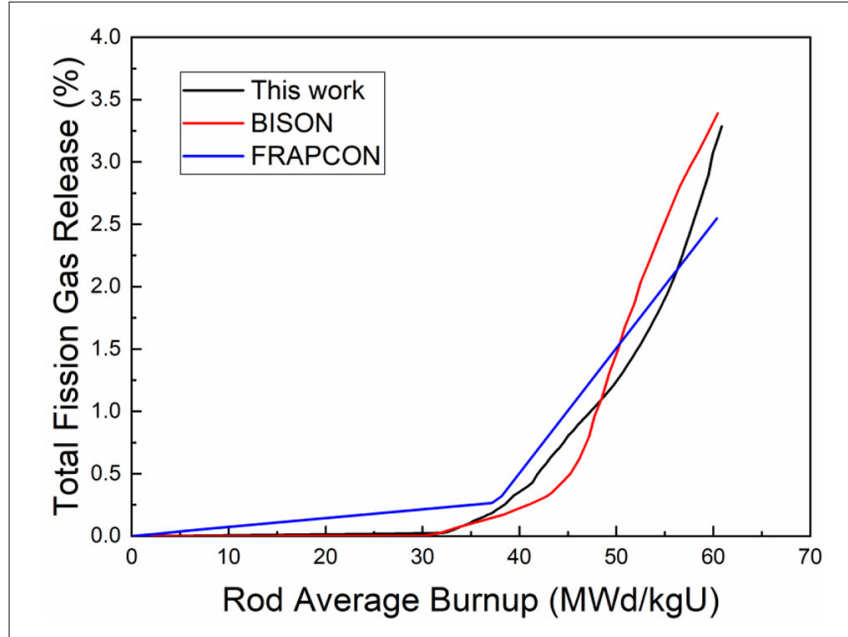

FIGURE 13 | Fission gas release for UN/SiC at $20 \mathrm{~kW} / \mathrm{m}$.

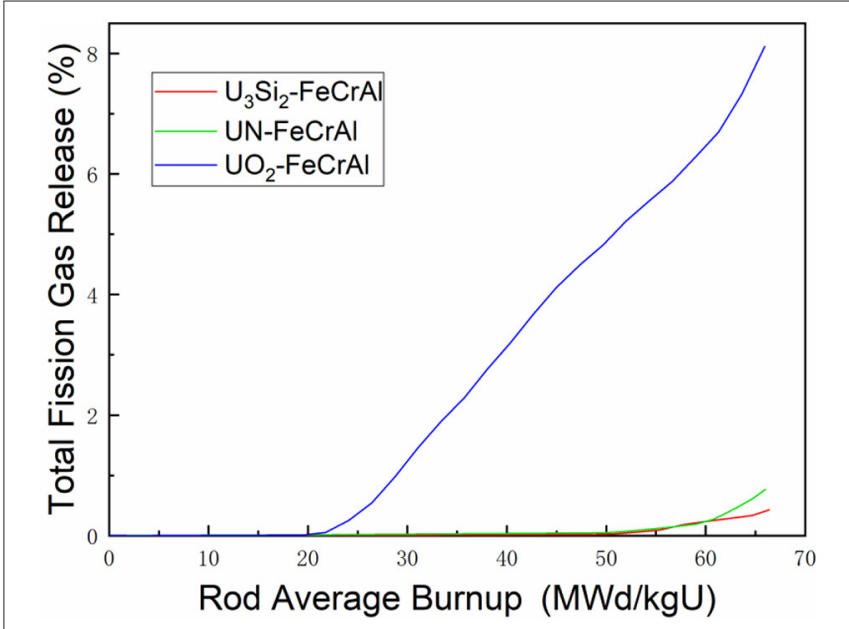

FIGURE 14 | Fission gas release for different materials at $20 \mathrm{~kW} / \mathrm{m}$. of $\mathrm{SiC}$ thermal conductivity under irradiation. Adoption of FeCrAl cladding causes lower fuel centerline temperature at high burnup when compared with the case of Zircaloy cladding. It is noticed that the adoption of ATF claddings can effectively delay the gap closure as well as the PCMI. A significant rise of hoop stress is found in both $\mathrm{FeCrAl}$ and $\mathrm{SiC}$ claddings after PCMI due to their higher stiffness and lower creep rate.

3. Under the same conditions, the fission gas release rates of UN and $\mathrm{U}_{3} \mathrm{Si}_{2}$ are lower than $\mathrm{UO}_{2}$.

\section{DATA AVAILABILITY STATEMENT}

The raw data supporting the conclusions of this article will be made available by the authors, without undue reservation.

\section{AUTHOR CONTRIBUTIONS}

ZZ: study of cladding material. PY: study of fuel materials. CX: study of gas release behavior. ZC: code development. YCh: manuscript proof. GS: manuscripy proof. ZY: manuscript proof. ZJ: FeCrAl models. HX: SiC models. YCe: neutronics study. All authors contributed to the article and approved the submitted version.

\section{FUNDING}

We thank the funding support from National key research and development program (No. 2018YFB1900400) and support from Nuclear Power Institute of China (Contract No. HT-ATF-142018001). 


\section{REFERENCES}

Barani, T., Pastore, G., Pizzocri, D., Andersson, D. A., Matthews, C., Alfonsi, A., et al. (2019). Multiscale modeling of fission gas behavior in U3Si2 under LWR conditions. J. Nucl. Mater. 522, 97-110. doi: 10.1016/j.jnucmat.2019. 04.037

Bernard, L. C., Jacoud, J. L., and Vesco, P. (2002). An efficient model for the analysis of fission gas release. J. Nucl. Mater. 302, 125-134. doi: 10.1016/S0022-3115(02)00793-6

Feng, B., Karahan, A., and Kazimi, M. S. (2011). "Steady-state nitride fuel behavior modeling with FRAPCON EP and its application to PWRs," in Proceedings of ICAPP (Charlotte, NC).

Finlay, M. R., Hofman, G. L., and Snelgrove, J. L. (2004). Irradiation behaviour of uranium silicide compounds. J. Nucl. Mater. 325, 118-128. doi: 10.1016/j.jnucmat.2003.11.009

Forsberg, K., and Massih, A. R. (1985). Diffusion theory of fission gas migration in irradiated nuclear fuel $\mathrm{UO}_{2}$. J. Nucl. Mater. 135, 140-148. doi: 10.1016/0022-3115(85)90071-6

Gamble, K. A., Pastore, G., Andersson, D., Cooper, M. W. (2019). ATF Material Model Development and Validation for Priority Fuel Concept. Idaho Falls, ID: Idaho National Lab. (INL). doi: 10.2172/1547325

Hales, J. D., Williamson, R. L., Novascone, S. R., Pastore, G., Spencer, B. W., Stafford, D. S., et al. (2015). BISON Theory Manual: The Equations behind Nuclear Fuel Analysis, BISON Release 1.2. Idaho Falls, ID: Idaho National Laboratory, INL/EXT-13-29930 Rev. 2.

Hayes, S. L., Thomas, J. K., and Peddicord, K. L. (1990a). Material property correlations for uranium mononitride: III. Transport properties. J. Nucl. Mater. 171, 289-299. doi: 10.1016/0022-3115(90)90376-X

Hayes, S. L., Thomas, J. K., and Peddicord, K. L. (1990b). Material property correlations for uranium mononitride: IV. Thermodynamic properties. J. Nucl. Mater. 171, 300-318. doi: 10.1016/0022-3115(90)90377-Y

He, Y., Chen, P., Wu, Y., Su, G. H., Tian, W., and Qiu, S. (2018). Preliminary evaluation of U3Si2-FeCrAl fuel performance in light water reactors through a multi-physics coupled way. Nucl. Eng. Des. 328, 27-35. doi: 10.1016/j.nucengdes.2017.12.019

Katoh, Y., Koyanagi, T., McDuffee, J. L., Snead, L. L., and Yueh, K. (2018). Dimensional stability and anisotropy of $\mathrm{SiC}$ and SiC-based composites in transition swelling regime. J. Nucl. Mater. 499, 471-479. doi: 10.1016/j.jnucmat.2017.12.009

Koyanagi, T., and Katoh, Y. (2018). Radial Thermal Conductivity Measurement for SiC Composite Tubes. Oak Ridge, TN: Oak Ridge National Lab (ORNL). doi: 10.2172/1479730

Koyanagi, T., Katoh, Y., Ozawa, K., Shimoda, K., Hinoki, T., and Snead, L. L. (2016). Neutron-irradiation creep of silicon carbide materials beyond the initial transient. J. Nucl. Mater. 478, 97-111. doi: 10.1016/j.jnucmat.2016. 06.006

Koyanagi, T., Katoh, Y., Singh, G., and Snead, M. (2017). SiC/SiC Cladding Materials Properties Handbook. Nuclear Technology Research and Development, ORNL/TM-2017/M-2385.

Li, W., and Shirvan, K. (2019). U3Si2-SiC fuel performance analysis in BISON during normal operation. Ann. Nucl. Energy 132, 34-45. doi: 10.1016/j.anucene.2019.04.021
Liu, R., Zhou, W., and Cai, J. (2018). Multiphysics modeling of accident tolerant fuel-cladding U3Si2-FeCrAl performance in a light water reactor. Nucl. Eng. Des. 330, 106-116. doi: 10.1016/j.nucengdes.2018.01.041

Metzger, K. E. (2016). Analysis of pellet cladding interaction and creep of U3Si2 fuel for use in light water reactors (Doctoral dissertation). University of South Carolina, Columbia, SC, United States.

Metzger, K. E., Knight, T. W., and Williamson, R. L. (2014). Model of U3Si2 Fuel System Using BISON Fuel Code. Idaho Falls, ID: Idaho National Laboratory (INL).

Olander, D. R. (1976). Fundamental Aspects of Nuclear Reactor Fuel Elements: Solutions to Problems. Department of Nuclear Engineering, California University, Berkeley, United States. doi: 10.2172/7290222

Qiu, B. W., Wang, J., Deng, Y. B., Wang, M. J., Wu, Y. W., and Qiu, S. Z. (2020). A review on thermohydraulic and mechanical-physical properties of $\mathrm{SiC}, \mathrm{FeCrAl}$ and $\mathrm{Ti}_{3} \mathrm{SiC}_{2}$ for ATF cladding. Nucl. Eng. Technol. 52, 1-13. doi: 10.1016/j.net.2019.07.030

Raju, S., Ganesh, B. J., Rai, A. K., Mythili, R., Saroja, S., Mohandas, E., et al. (2009). Measurement of transformation temperatures and specific heat capacity of tungsten added reduced activation ferritic-martensitic steel. J. Nucl. Mater. 389, 385-393. doi: 10.1016/j.jnucmat.2009.02.030

Rice, A. (2015). Intercode advanced fuels and cladding comparison using bison, frapcon, and femaxi fuel performance codes.

Snead, L. L., Nozawa, T., Katoh, Y., Byun, T. S., Kondo, S., and Petti, D. A. (2007). Handbook of SiC properties for fuel performance modeling. J. Nucl. Mater. 371, 329-377. doi: 10.1016/j.jnucmat.2007.05.016

Sweet, R. T. (2018). Thermo-mechanical analysis of iron-chromium-aluminum (FeCrAl) alloy cladding for light water reactor fuel elements (Doctor of Philosophy). University of Tennessee, Knoxville, TN, United States.

Sweet, R. T., George, N. M., Maldonado, G. I., Terrani, K. A., and Wirth, B. D. (2018). Fuel performance simulation of iron-chrome-aluminum (FeCrAl) cladding during steady-state LWR operation. Nucl. Eng. Des. 328, 10-26. doi: $10.1016 /$ j.nucengdes.2017.11.043

White, J. T. (2018). Update to the U3Si2 Property Handbook. Los Alamos: US Department of Energy.

Williamson, R. L. (2011). Enhancing the ABAQUS thermomechanics code to simulate multipellet steady and transient LWR fuel rod behavior. J. Nucl. Mater. 415, 74-83. doi: 10.1016/j.jnucmat.2011.05.044

Yamamoto, Y., Snead, M. A., Field, K. G., Terrani, K. A. (2017). Handbook of the Materials Properties of FeCrAl Alloys for Nuclear Power Production Applications. Oak Ridge, TN: Oak Ridge National Lab (ORNL). doi: 10.2172/1400207

Conflict of Interest: The authors declare that the research was conducted in the absence of any commercial or financial relationships that could be construed as a potential conflict of interest.

Copyright (c) 2021 Zeng, Pan, Chen, Zhang, Yin, Gao, Zhou, Zhang, He and Yuan. This is an open-access article distributed under the terms of the Creative Commons Attribution License (CC BY). The use, distribution or reproduction in other forums is permitted, provided the original author(s) and the copyright owner(s) are credited and that the original publication in this journal is cited, in accordance with accepted academic practice. No use, distribution or reproduction is permitted which does not comply with these terms. 